\title{
Factors Affecting Age at Initial Autism Spectrum Disorder Diagnosis in a National Survey
}

\author{
Rebecca E. Rosenberg, ${ }^{1}$ Rebecca Landa, ${ }^{2,3}$ J. Kiely Law,, 4 \\ Elizabeth A. Stuart, ${ }^{5}$ and Paul A. Law ${ }^{1,2,4,5}$ \\ ${ }^{1}$ Department of Medical Informatics, Kennedy Krieger Institute, Baltimore, MD 21211, USA \\ ${ }^{2}$ Center for Autism and Related Disorders, Kennedy Krieger Institute, Baltimore, MD 21211, USA \\ ${ }^{3}$ Department of Psychiatry, Johns Hopkins University School of Medicine, Baltimore, MD 21205, USA \\ ${ }^{4}$ Department of Pediatrics, Johns Hopkins University School of Medicine, Baltimore, MD 21205, USA \\ ${ }^{5}$ Department of Mental Health, Johns Hopkins Bloomberg School of Public Health, Baltimore, MD 21205, USA
}

Correspondence should be addressed to Paul A. Law, lawp@kennedykrieger.org

Received 6 January 2011; Revised 12 April 2011; Accepted 19 May 2011

Academic Editor: Gregory S. Liptak

Copyright () 2011 Rebecca E. Rosenberg et al. This is an open access article distributed under the Creative Commons Attribution License, which permits unrestricted use, distribution, and reproduction in any medium, provided the original work is properly cited.

\begin{abstract}
Entry into early intervention depends on both age of first parent concern (AOC) and age at initial autism spectrum disorder (ASD) diagnosis (AOD). Using data collected from a national online registry from 6214 children diagnosed with an ASD between 1994 and 2010 in the US, we analyzed the effect of individual, family, and geographic covariates on AOC and AOD in a multivariate linear regression model with random effects. Overall, no single modifiable factor associated with AOC or AOD emerged but cumulative variation in certain individual- and family-based features, as well as some geographic factors, all contribute to AOC and AOD variation. A multipronged strategy is needed for targeted education and awareness campaigns to maximize outcomes and decrease disparities in ASD care.
\end{abstract}

\section{Introduction}

The diagnosis of autism spectrum disorders (ASDs), a group of neuropsychiatric disorders characterized by social and communication deficits and repetitive behaviors, has become increasingly common [1], affecting more than one in 110 children in the US [2]. Current subtypes in the American Psychiatric Association's Diagnostic and Statistical Manual of Mental Disorders (text revision) (DSM IV-TR) [3] include autistic disorder $(\mathrm{AD})$, pervasive developmental disordernot otherwise specified (PDD-NOS), and Asperger disorder (colloquially, Asperger syndrome; AS) and are referred to collectively in this paper, along with other community diagnoses such as "PDD" and "ASD", as the autism spectrum disorders (ASDs).

Lifetime costs for an individual with ASD can exceed $\$ 1.2$ million $[4,5]$, and there is no known prevention or cure. Because early intervention has been shown to improve levels of functioning and rate of development, prompt access to effective $[6,7]$ early intervention services may ultimately permit less restrictive and less expensive educational placements. The gains in child functioning made possible through early intervention may also [8] be associated with reduced family and community burden [9-12].

Timely diagnosis is critical for enrollment in intervention services as early in life as possible, in order to capitalize on neuroplasticity [13]. Although diagnosis of ASD is possible in children as young as 14 months of age [13], most children with autism are not diagnosed until after three years of age $[14,15]$. Understanding factors associated with delay in diagnosis, including both timing of age of parent concern (AOC) and age of initial diagnosis (AOD), may inform public awareness campaigns, screening guidelines, and professional education programming with the aim of lowering the age at which autism is detected. This would result in earlier access to intervention for children with autism.

Age of parent concern about developmental delays or atypical patterns may be as early as birth for some 
children [16], but average AOC in ASD occurs around 12 to 18 months [16-22] and typically involves social and communication skills $[16,17,23,24]$. Variation in AOC may reflect true differences in developmental trajectories of ASD subtypes or underlying causes [25-28], but there is limited or conflicting research on the effects of gender, family, community, and secular factors on AOC $[25,26,29-$ 31].

AOD has been more closely examined in the literature. Estimates of average AOD in ASD vary, ranging from 3.9 to 5.7 years depending on research design [14, 32-38]. Certain characteristics have consistently emerged as factors affecting AOD, including specific diagnosis; age of diagnosis for $\mathrm{AD}$ (3.1 to 5.5 years) or PDD-NOS (3.9 to 4.2 years) is much younger than average age of AS diagnosis (7 to 9 years) $[14,25,34,38,39]$. At the family level, higher parent education and affluence are associated with earlier AOD and increased likelihood of diagnosis [38, 40-43]. Local and systems factors, such as increased rurality and lower community affluence, have been associated with delays in AOD [33, 40-42, 44, 45].

Identification of significant and modifiable factors affecting AOC and AOD is critical to effective ASD-specific early intervention that maximizes outcomes. The previous literature on $\mathrm{AOC}$ and $\mathrm{AOD}$ has not integrated, into one study, both AOC and AOD, child factors (such as intellectual functioning, birth order, history of regression, initial ASD diagnosis), family context factors (such as maternal education, race/ethnicity), and geographical factors (such as region and county income). Further, while the largest epidemiologic [33] and administrative database [14] studies of AOD have examined multiple factors associated with AOD, neither had examined the AOC in the same population. As well, factors such as history of autistic regression and intellectual disability and family socioeconomic status were not included.

Therefore, in an effort to identify modifiable opportunities for optimizing early intervention, our goals in this study were to identify and confirm parent-reported individual, family and geographic factors influencing $A O C$ and $A O D$ using the largest ASD dataset to date, an online open national registry, the Interactive Autism Network (IAN), and a registry with validated [46] and verified [47] parentreported data. We hypothesized, based on the literature, that AOD but not AOC is affected by individual factors such as race, ethnicity, diagnosis, and gender, and family factors like maternal education, as well as by systems factors such as region and county income [25, 26, 29-31]. Identifying such variability could then help clinicians, families, and policymakers focus on interventions to reduce disparities in ASD care.

\section{Method}

2.1. Participants. To investigate factors associated with variation in ages of first concern and diagnosis, we used the online Interactive Autism Network (IAN) database. IAN is an online US-based research database begun in April 2007 [48], with more than 33,000 individuals enrolled as of
July 2010, including more than 13,000 affected individuals with professionally diagnosed ASD and their immediate family members (http://www.ianproject.org/). Families are recruited through a variety of mechanisms, including online media, provider referral, and support groups. All data are submitted by families who electronically consent, under the auspices of the Johns Hopkins Medicine Institutional Review Board (\#NA_00002750). The database is continually updated and recruitment is ongoing.

The current analysis was conducted with data extracted on July 1, 2010, from all subjects aged 0 to 21 years at the time of primary history questionnaire completion $(n=$ 7871) with a diagnosis other than childhood disintegrative disorder; some evaluators use non-DSM-IV-TR labels such as "ASD" or "PDD", referred to in this paper as "Other ASD". Participants were excluded if our database did not contain information on maternal education $(n=428)$, date of initial diagnosis (month and year), inconsistent or missing date of diagnosis $(n=1073)$ or missing initial diagnosis $(n=14)$, or diagnosed before $1994(n=48)$, since the overall $n$ for those years was $<30$ each year. We excluded all data from participants whose parents did not express concern prior to the time of diagnosis or did not provide any information on AOC $(n=25)$, who reported AOC that conflicted with AOD $(n=57)$ outside the range for estimation error or due to recall (e.g., $\mathrm{AOC}=3$ years and $\mathrm{AOD}=1.5$ years) or due to concerns of overall reliability, leaving a total of 6214 participants.

2.2. Measures. The IAN Project data collection consists of multiple topic-specific forms, authored by the IAN Research team in collaboration with other researchers. Questionnaires are available at http://www.iancommunity.org/cs/ian_research_questions/ian_research_questions. All families complete the initial registration and then are invited to complete several other questionnaires including a profile on each affected child. These surveys were developed by IAN staff in collaboration with members of the IAN Science Advisory Committee, piloted with families, and revised as needed.

Our dependent variables were AOC and AOD. For AOC, parents were asked, "At what age did you first have concerns about your child's development?". Parents could report openended AOC and/or 6-month-interval categories. For ease of presentation of AOC, the midpoint of each category was used when only approximate AOC interval was reported; for example, if concern was "Birth-6 months", then 3 months was the AOC. This pattern was used for all participants missing specific age at concern $(n=248)$, thereby equally distributing any biases.

For AOD, parents were asked specific date of initial ASD diagnosis. AOD was calculated by comparing date of birth and date of diagnosis. If parents gave only the month and year of diagnosis, then day of diagnosis was imputed as the midpoint (15th) of the month to enable consistent calculation of AOD. All participants included at least month/year for AOD.

Independent variables extracted from the IAN database questionnaire responses included initial ASD diagnosis, race, 
gender, birth date, initial evaluator, birth order, history of skill loss, and current address. The race variable corresponded to a category delineated by the U.S. Census Bureau and was eventually collapsed into four categories because of cell size: White, Black/African American, multiracial, and other. For the variable of intellectual disability (ID) status, participants were categorized as ID if they either (a) reported ever receiving a diagnosis of "mental retardation" or (b) reported an IQ score of $<70$. Exact timing of ID diagnosis in relation to ASD diagnosis is not reported.

For history of skill loss, we reclassified skill loss as "autistic regression" if parents reported moderate to severe social or communication skills lost before age 3 .

Regions were defined according to the U.S. Census Bureau, with Delaware and Maryland grouped into the Northeast [49]. Data on county urbanicity/rurality, county median income, and county racial distribution were assigned by matching Federal Information Processing Standards codes with federal data [50]. These six subgroups were later collapsed into two groups: large central or fringe metropolitan (principal city $\geq 1$ million) and rural to medium metropoli$\tan$ (metropolitan statistical area $<1$ million; micropolitan; rural).

For county median income and county percentage white, categories were distributed by national quartiles.

Data on maternal education were extracted from IAN questionnaires; only $10 \%$ of biological fathers had completed forms; therefore, no paternal data were included; education data is linked to the parent filling out the form and hence, paternal education is not elicited from maternal forms (and vice versa). Maternal education history was eventually divided into two categories based on completion of bachelor's degree.

If families skipped a question based on an answer to the previous question, answered do not know, or declined to answer a question, data were recorded as missing.

All survey data were entered by parents and maintained in the Internet Mediated Research System, IMRS (MDLogix, Baltimore, MD).

2.3. Statistical Analysis. Analyses were performed using STATA 11.0 (College Station, TX). Within individual analyses, we used the model-wise complete case approach to handling missing data, whereby those with missing data for a given model were not included in that analysis.

Initial testing showed that $\mathrm{AOC}$ and $\mathrm{AOD}$ variables are not normally distributed. Therefore, both dependent outcomes were log-transformed; doing so approached a normal distribution for both AOC and AOD compared with other transformation techniques like squaring or inversion. For analysis of each independent variable's association with transformed $\mathrm{AOC}$ and $\mathrm{AOD}$, univariate linear regression was used to identify those variables with $P<.10$ for inclusion in the multivariate model.

We then used multivariate linear regression (xtreg) with state-level clustered random effects, to examine the associations of significant covariates along with a priori independent variables (gender, current age, race, ethnicity, maternal education, and era of diagnosis) with the logtransformed dependent outcomes: age at first parent concern (AOC) and age at first diagnosis (AOD). The AOD model also included geographic characteristics (region, county median income quartiles, county percentage white quartiles, binary rurality) to reflect potential variation in access to diagnostic services and pediatric specialists. The random effects approach helps to correct for uncertain potential similarities clustered among certain groups; in this instance, these groups are residents of the same state.

To interpret the results of the multivariate linear regression of log-transformed data, the coefficient was multiplied by the referent group base value, yielding difference in months between referent group and the analyzed factor, all other factors held equal.

To assess contribution of different levels of independent variables to $\mathrm{AOC}$ and $\mathrm{AOD}$, we assessed differences in pseudo-R-squared between each model. We then used likelihood ratio testing to test differences between nested models for AOC and AOD: base model (individual: gender, age, initial diagnosis, history of autistic regression and/or ID, high-risk (AOC only)); family characteristics (firstborn, race, ethnicity, maternal education); and geographic characteristics (region, county affluence and racial composition, rurality).

\section{Results}

Mean AOC in our registry of children of all ages (Table 1) diagnosed between 2004 and 2010 was 19.6 months (SD = 15.0), and median AOC was 18 months (interquartile range [IQR], 11.0-24.0). Mean AOD was 47.9 months $(\mathrm{SD}=30.8)$ with a median AOD of 36.9 months (IQR 27.8, 56.4). Among those $>8$ years old, mean unadjusted AOD was 57.7 months $(\mathrm{SD}=35.3)$.

As seen in Table 1, unadjusted univariate log-transformed mean AOC was later for male, African-American or Asian-American, Hispanic, and older children as well as those with initial diagnosis other than autistic disorder (AD), and firstborn status. History of intellectual disability (ID) or medical problems (extreme prematurity, cerebral palsy, and/or seizure disorder) was univariately associated with earlier AOC. Maternal education, chronological era, and geographic factors did not affect AOC.

Mean log-transformed AOD in univariate analysis differed significantly by ethnicity, age, specific initial ASD diagnosis, birth order, and history of autistic regression; by maternal education; county percent white, rurality, region, and age category (Table 1).

For AOC, likelihood ratio testing found significant differences in model fit with the addition of family-level characteristics (ethnicity, race, maternal education, firstborn) to individual characteristics (gender, first diagnosis, history of regression, history of intellectual disability) (LR chi-sq 43.0, $P<.001)$ but not with subsequent addition of geographic factors (LR chi-sq 18.39, $P=.073$ ). Therefore, these geographic factors were not included in the multivariate model. 
TABLE 1: Comparison of mean age of first concern (AOC) and age of first diagnosis (AOD) by characteristic $(N=6214)$; univariate testing by ANOVA on log-transformed AOC and AOD.

\begin{tabular}{|c|c|c|c|c|c|}
\hline Characteristic & $N$ & $\begin{array}{c}\text { Mean age at first } \\
\text { concern }(\mathrm{AOC}), \\
\text { mo. }(\mathrm{SD})^{*}\end{array}$ & $\begin{array}{c}\text { ANOVA } \\
P \text { value/median }\end{array}$ & $\begin{array}{l}\text { Mean age at first } \\
\text { diagnosis }(\mathrm{AOD}), \\
\text { mo. }(\mathrm{SD})^{*}\end{array}$ & $\begin{array}{c}\text { ANOVA } \\
P \text { value/median }\end{array}$ \\
\hline Overall & 6214 & $19.6(15.0)$ & & $47.6(30.8)$ & \\
\hline Median & & & 18 (IQR 11,24) & & $\begin{array}{c}36.9 \\
(\text { IQR } 27.8,56.4)\end{array}$ \\
\hline Gender & & & $<.001$ & & .796 \\
\hline Male & 5119 & 19.8 & & 47.6 & \\
\hline Female & 1095 & 18.6 & & 49.0 & \\
\hline Race & & & .048 & & .367 \\
\hline White & 5491 & 19.5 & & 47.8 & \\
\hline African-American & 165 & 21.7 & & 49.2 & \\
\hline Asian/Asian-American & 57 & 21.7 & & 45.8 & \\
\hline Multiracial & 244 & 18.7 & & 50.0 & \\
\hline Other/unknown & 257 & 19.6 & & 46.4 & \\
\hline Ethnicity & & & $<.05$ & & .004 \\
\hline Hispanic & 5709 & 19.9 & & 44.0 & \\
\hline Not Hispanic & 505 & 19.5 & & 48.2 & \\
\hline Current age, years* & & & $<.001$ & & $<.001$ \\
\hline $0-5$ & 940 & 14.4 & & 29.0 & \\
\hline $6-11$ & 3692 & 18.7 & & 42.4 & \\
\hline $12-18$ & 1582 & 24.7 & & 71.9 & \\
\hline Initial ASD Diagnosis & & & $<.001$ & & $<.001$ \\
\hline Autism & 2535 & 10.5 & & 38.3 & \\
\hline PDD-NOS ${ }^{\mathrm{a}}$ & 1893 & 13.5 & & 44.9 & \\
\hline Asperger & 891 & 24.4 & & 87.8 & \\
\hline Other ASD & 895 & 11.9 & & 41.7 & \\
\hline Intellectual disability ${ }^{\mathrm{b}}$ (ID) & & & $<.001$ & & .194 \\
\hline Present & 1229 & 17.8 & & 48.3 & \\
\hline Absent & 4971 & 20.0 & & 47.8 & \\
\hline Firstborn & 3242 & 20.6 & $<.001$ & 49.1 & $<.001$ \\
\hline Not firstborn & 2971 & 18.5 & & 46.5 & \\
\hline History of autistic regression & 1511 & 16.9 & .854 & 38.2 & $<.001$ \\
\hline No regression & 4703 & 20.4 & & 51.0 & \\
\hline High-risk ${ }^{c}$ & & & $<.001$ & & .535 \\
\hline Yes & 650 & 16.0 & & 47.4 & \\
\hline No & 5563 & 20.0 & & 47.9 & \\
\hline Multiplex family & & & .255 & & .776 \\
\hline Yes & 872 & 21.0 & & 49.4 & \\
\hline No & 5342 & 19.3 & & 47.6 & \\
\hline Era of Initial Diagnosis & & & .601 & & $<.001$ \\
\hline $1994-2000$ & 850 & 18.5 & & 39.3 & \\
\hline $2001-2008$ & 5364 & 19.7 & & 49.2 & \\
\hline Maternal education & & & .468 & & .007 \\
\hline$\leq$ College diploma & 3098 & 19.5 & & 48.9 & \\
\hline
\end{tabular}


TABle 1: Continued.

\begin{tabular}{|c|c|c|c|c|c|}
\hline Characteristic & $N$ & $\begin{array}{c}\text { Mean age at first } \\
\text { concern (AOC), } \\
\text { mo. }(\mathrm{SD})^{*}\end{array}$ & $\begin{array}{c}\text { ANOVA } \\
P \text { value/median }\end{array}$ & $\begin{array}{l}\text { Mean age at first } \\
\text { diagnosis (AOD), } \\
\text { mo. (SD)* }\end{array}$ & $\begin{array}{c}\text { ANOVA } \\
P \text { value } / \text { median }\end{array}$ \\
\hline College+ & 3116 & 19.6 & & 46.8 & \\
\hline County median income & & & .537 & & $<.001$ \\
\hline Lowest quartile & 171 & 14.9 & & 46.6 & \\
\hline 2nd quartile & 486 & 14.9 & & 47.2 & \\
\hline 3rd quartile & 1211 & 16.3 & & 51.1 & \\
\hline 4th quartile & 4344 & 14.7 & & 49.9 & \\
\hline County percent white & & & .494 & & $<.001$ \\
\hline Lowest quartile & 2206 & 19.3 & & 46.6 & \\
\hline 2nd quartile & 2453 & 19.4 & & 47.2 & \\
\hline 3rd quartile & 1178 & 20.6 & & 51.0 & \\
\hline 4th quartile & 375 & 19.4 & & 49.9 & \\
\hline Rurality ${ }^{50}$ & & & .595 & & $<.001$ \\
\hline Large central metro & 1364 & 19.6 & & 45.1 & \\
\hline Large fringe metro & 2104 & 19.2 & & 46.0 & \\
\hline Medium metro & 1303 & 19.3 & & 48.5 & \\
\hline Small metro & 644 & 20.8 & & 53.6 & \\
\hline Micropolitan & 538 & 20.5 & & 51.2 & \\
\hline Noncore (rural) & 261 & 18.2 & & 52.2 & \\
\hline Binary rural & & & .621 & & $<.001$ \\
\hline Principal city $\geq 1$ million & 368 & 19.4 & & 45.7 & \\
\hline Principal city $<1$ million & 2746 & 19.8 & & 50.6 & \\
\hline US Region & & & .311 & & $<.001$ \\
\hline Northeast & 1843 & 18.9 & & 44.8 & \\
\hline South & 1808 & 19.4 & & 50.1 & \\
\hline Midwest & 1434 & 20.5 & & 49.8 & \\
\hline West & 1129 & 19.6 & & 46.7 & \\
\hline
\end{tabular}

Note -: not significant. Some totals in categories do not add up to 6214 due to missing data. aPDD-NOS: Pervasive Developmental Disorder-Not Otherwise Specified.

bID: Intellectual disability/mental retardation.

${ }^{\mathrm{c}}$ High risk: history of prematurity (<34 weeks gestational age) and/or seizures and/or cerebral palsy; sibling with ASD not included.

Multivariate linear regression analysis of log-transformed AOC, adjusted by age, is shown in Table 2 . The referent group in the AOC analysis was white, non-Hispanic, nonfirstborn males diagnosed with $\mathrm{AD}$ and with a history of ID and medical high-risk without regression; mean AOC for this group was 10.3 months. Parents of African-American or Hispanic children reported 1.94 and 1.56 mo later AOC than white or non-Hispanic children, respectively. Maternal education did not affect AOC. The largest risk factor for later AOC was initial diagnosis of AS (2.93 mo); the largest correlate for early AOC was high medical risk (2.8 mo earlier than reference). Children who were firstborn had 1 mo later AOC than the referent group.

Inclusion of a gender-diagnosis interaction term was not significant in AOC.

In multivariate analysis of $\mathrm{AOD}$, there were significant increases in model fit with the addition of each layer of characteristics: LR test individual with family, LR $\mathrm{chi}^{2}=$ 51.03, $P<.001 ;$ LR test individual-family with addition of geographic characteristics, LR $\mathrm{chi}^{2}=1930.16, P<.001$. Adjusted $r$-squares for each model were $0.427,0.432$, and 0.582 , respectively.

In Table 3, results of log-transformed AOD multivariate linear regression with clustering for state are shown. The referent group was white male, non-Hispanic children with initial diagnosis of $\mathrm{AD}$ without comorbid ID, autistic regression or firstborn, with lower maternal education, living in the area with lowest white quartile, lowest income quartile, and large metropolitan area. Average AOD was 14.7 months in this calculated group.

An interaction term with gender and diagnosis in AOD was tested but was not included due to collinearity in the ultimate model.

Statistically significant risk factors for 1 mo delay in AOD included black or multiracial race $(1.08,1.45)$, living in neither poor nor wealthy counties (middle quartiles, 1.551.07 mo later), living in rural areas (.74 mo later), and living in a region other than the North East (1.5-1.7 mo later). Both 
TABLE 2: Multivariate linear regression of factors affecting log-transformed age at first parent concern (AOC) among 6214 individuals with ASD.

\begin{tabular}{|c|c|c|c|c|c|}
\hline \multirow{2}{*}{$\begin{array}{l}\text { Parameter } \\
\text { Female gender }\end{array}$} & \multirow{2}{*}{$\begin{array}{c}\text { Raw coefficient } \\
-0.08\end{array}$} & \multirow{2}{*}{$\begin{array}{l}\text { Converted average difference in } \\
\text { AOC compared with reference } \\
\text { group (in mo) }\end{array}$} & \multicolumn{2}{|c|}{$95 \% \mathrm{CI}$ (in mo) } & \multirow{2}{*}{$\begin{array}{c}P \\
.009\end{array}$} \\
\hline & & & -1.33 & -0.21 & \\
\hline \multicolumn{6}{|l|}{ Race } \\
\hline White & REF & & & & \\
\hline Black/African-American & 0.17 & 1.94 & 0.36 & 3.77 & .015 \\
\hline Multiracial & -0.07 & -0.74 & -1.77 & 0.45 & - \\
\hline Other & 0.04 & 0.38 & -0.72 & 1.60 & - \\
\hline Hispanic Ethnicity & 0.14 & 1.56 & 0.58 & 2.63 & .001 \\
\hline \multicolumn{6}{|l|}{ Initial diagnosis } \\
\hline Autistic disorder & REF & & & & \\
\hline PDD-NOS ${ }^{\mathrm{a}}$ & 0.05 & 0.55 & -0.03 & 1.15 & .060 \\
\hline Asperger Syndrome & 0.25 & 2.93 & 2.00 & 3.95 & $<.001$ \\
\hline Other ASD & -0.01 & -0.08 & -0.75 & 0.66 & - \\
\hline Presence of ID ${ }^{b}$ & -0.13 & -1.27 & -1.79 & -0.72 & $<.001$ \\
\hline Firstborn & 0.10 & 1.03 & 0.54 & 1.56 & $<.001$ \\
\hline High risk $^{\mathrm{c}}$ & -0.32 & -2.82 & -3.35 & -2.25 & $<.001$ \\
\hline History of autistic regression & 0.06 & 0.58 & 0.03 & 1.18 & .042 \\
\hline
\end{tabular}

Adjusted by age.

Note - $: P>.05$, statistical nonsignificance.

aPDD-NOS: Pervasive Developmental Disorder-Not Otherwise Specified.

${ }^{b}$ ID: Intellectual disability/mental retardation.

${ }^{\mathrm{c}}$ High risk: history of prematurity and/or seizures and/or cerebral palsy.

ID and history of autistic regression were associated with earlier AOD. Initial diagnosis with AS was associated with over one-year later AOD than the referent group. Graduate maternal education had minimal ( 0.3 month earlier) effect on AOD.

\section{Discussion}

Overall, our data suggest that even among higher-resource families enrolled in an online voluntary national autism registry, individual and family factors contribute to variation in AOD and somewhat with AOC. AOD is also affected by variation in geographic characteristics.

4.1. Age of Parent Concern (AOC). We confirmed previous research on certain individual characteristics associated with earlier AOC and AOD, including history of early medical problems $[26,33]$ and later AOC and AOD for firstborn children $[23,25,26,51]$ and those with non-AD diagnoses [39]. Because of the wording of the AOC question, which was nonspecific to type of developmental concern, it was not surprising that those children with medical risk factors or history of ID were also more likely to have earlier AOC.

The findings of earlier AOC for girls confirmed some previous studies showing slight but statistically significant earlier concern for girls with abnormal development [25, 28]. This slight variation may be due in part to initially earlier communication skills in girls than boys [52], such that a delay in a female is more atypical and is apparent to families and clinicians than in a male; this disparity deserves further consideration given that the model already includes diagnosis with varying degrees of gender disparity for AS versus other diagnoses.

Delays in AOC for both African-American and Hispanic children have been reported in one other published study [28]; many others, including those of a Medicaid cohort, found no difference $[25,26,29-31]$. Our findings are temporized by the overall small cell size $(<3 \%)$ of underrepresented minorities; some have postulated that disparities in perception of ASD and behavior problems suggest that the way that different communities perceive and act on atypical behaviors can vary [53]. Further study of AOC in underrepresented populations with more socioeconomic diversity would have more power to elucidate true differences and establish effective interventions $[54,55]$.

4.2. Age of Diagnosis (AOD). As expected, we found that initial diagnosis other than autistic disorder, especially AS, contributed to significantly delayed AOD, which follows the natural history of the disorder and the often milder presentation in PDD-NOS and AS [14, 33, 38, 39]. Presence of comorbid intellectual disability (ID) was associated with minimally earlier AOD, complementing previous reports finding either a lack of or inverse association between degree of ID or functional ability and AOD [33, 34]. Future studies examining variation by functional ability or degree of 
TABLE 3: Multivariate random-effects linear regression model (clustering by state) of log-transformed age at initial ASD diagnosis (AOD), adjusted by age and age of concern $(n=6214)$.

\begin{tabular}{|c|c|c|c|c|c|}
\hline Parameter & Raw coefficient & $\begin{array}{l}\text { Average difference in AOD } \\
\text { compared with reference group } \\
\text { (in mo })^{*}\end{array}$ & \multicolumn{2}{|c|}{ 95\% CI Difference (in mo) } & $P$ \\
\hline \multicolumn{6}{|l|}{ Gender } \\
\hline Male & REF & & & & \\
\hline Female & 0.04 & 0.46 & 0.06 & 0.87 & $<.025$ \\
\hline \multicolumn{6}{|l|}{ Race } \\
\hline White & REF & & & & \\
\hline African-American & 0.08 & 1.08 & 0.1 & 2.12 & .031 \\
\hline Multiracial & 0.10 & 1.45 & 0.62 & 2.33 & $<.001$ \\
\hline Other & 0.06 & 0.82 & 0.07 & 1.6 & .032 \\
\hline \multicolumn{6}{|l|}{ Ethnicity } \\
\hline Hispanic & -0.02 & -.16 & -0.73 & 0.44 & - \\
\hline Not Hispanic & REF & & & & \\
\hline \multicolumn{6}{|l|}{ Initial ASD Diagnosis } \\
\hline Autism & REF & & & & \\
\hline PDD-NOS ${ }^{\mathrm{a}}$ & 0.09 & 1.32 & 0.92 & 1.72 & $<.001$ \\
\hline Asperger & 0.62 & 12.39 & 11.49 & 13.32 & $<.001$ \\
\hline Other ASD & 0.08 & 1.16 & 0.67 & 1.66 & $<.001$ \\
\hline \multicolumn{6}{|l|}{ Intellectual disability ${ }^{\mathrm{b}}$ (ID) } \\
\hline Present & -0.05 & -0.67 & -1.04 & -0.28 & $<.001$ \\
\hline Absent & REF & & & & \\
\hline Firstborn & 0.03 & 0.36 & 0.05 & 0.67 & .024 \\
\hline Not firstborn & REF & & & & \\
\hline History of autistic regression & -0.08 & -1.05 & -1.38 & -0.72 & $<.001$ \\
\hline No regression & REF & & & & \\
\hline \multicolumn{6}{|l|}{ Maternal education } \\
\hline$\leq$ College diploma & REF & & & & \\
\hline College diploma & -0.02 & -0.27 & -0.42 & -0.12 & $<.001$ \\
\hline \multicolumn{6}{|l|}{ County median income } \\
\hline Lowest quartile & REF & & & & \\
\hline 2nd quartile & 0.1 & 1.55 & 0.43 & 2.76 & .006 \\
\hline 3rd quartile & 0.08 & 1.07 & 0.06 & 2.15 & .038 \\
\hline 4th quartile & 0.05 & 0.63 & -0.35 & 1.67 & - \\
\hline \multicolumn{6}{|l|}{ County percent white } \\
\hline Lowest quartile & REF & & & & \\
\hline 2nd quartile & 0.02 & 0.20 & -0.18 & 0.58 & - \\
\hline 3rd quartile & 0.05 & 0.63 & 0.14 & 1.13 & .012 \\
\hline 4th quartile & 0.05 & 0.66 & -0.08 & 1.43 & - \\
\hline \multicolumn{6}{|l|}{ Rurality } \\
\hline Metropolitan/peri-metro & REF & & & & \\
\hline Large/small town/rural & 0.05 & 0.74 & 0.37 & 1.12 & $<.001$ \\
\hline
\end{tabular}


Table 3: Continued.

\begin{tabular}{lcccc}
\hline Parameter & Raw coefficient & $\begin{array}{c}\text { Average difference in AOD } \\
\text { compared with reference group } \\
\text { (in mo) }\end{array}$ & 95\% CI Difference (in mo) & $P$ \\
\hline $\begin{array}{l}\text { Region } \\
\text { Northeast }\end{array}$ & REF & & & \\
South & 0.11 & 1.69 & 1.23 & 2.16 \\
Midwest & 0.11 & 1.65 & 1.18 & $<.001$ \\
West & 0.1 & 1.46 & 0.95 & $<.001$ \\
\hline
\end{tabular}

Adjusted by current age and log age of concern (AOC).

Note $-: P>.05$, statistical nonsignificance.

${ }^{a}$ PDD-NOS: Pervasive Developmental Disorder-Not Otherwise Specified.

${ }^{b}$ ID: Intellectual disability/mental retardation.

${ }^{\mathrm{c}}$ High risk: history of prematurity and/or seizures and/or cerebral palsy.

autism would be a better, more complete marker of role of impairment in predicting ASD diagnosis timing.

Our study suggested that gender contributes to slightly later $\mathrm{AOD}$, analogous to findings by other studies [33, 36, 38]. This is contrary to findings demonstrated in a large Medicaid sample [14] and other studies [25, 26, 34, 56]. Given that girls have earlier AOC, later AOD (adjusted for AOC) suggests a confounding effect of gender which may be more linked to the well-known increased gender imbalance in diagnosed AS $(\sim 10: 1)$ compared with other ASD $(4: 1)$ [57].

There were disparities by race in AOD as well, confirming past research in the US $[32,58]$ and internationally $[59]$, but not seen in the largest surveillance study [33]. Although these findings are not individually clinically significant, viewed from the aggregate level, they suggest vulnerability even among the higher SES families of IAN. Further qualitative studies and interventions should focus on identifying issues of differential access, community and/or health care risk perception, and other barriers to timely AOD among children of color. Future quantitative studies with larger sample sizes of underrepresented minorities are needed to examine interaction between race and potential confounders.

Hispanic ethnicity (of English-speaking families), however, was not a risk factor for AOD differences, similar to the findings of the only comprehensive large, multisite epidemiologic surveillance study of ASD surveillance [33], a large Medicaid study [14], and other parent-report surveys $[41,56]$ although this is less consistent with studies using administrative data $[32,43,55,58,60]$. Because ours is a sample of convenience skewed toward a highly involved and more educated parent base, those children who remain undiagnosed are not included; selection bias is a possible cause of these findings, especially given that IAN is currently only available in English.

We confirmed previous studies suggesting that higher maternal education was statistically associated with earlier AOD $[25,26,30,45]$, but the difference ( 0.3 months) is not clinically significant in a multivariate model, suggesting that other individual characteristics outweigh SES in predicting AOD, as was also reported by Shattuck et al. [33], at least among highly motivated families who participate in IAN. Further qualitative studies examining persistence and determination qualities ("advocacy") regardless of financial or educational resources by families in obtaining a diagnosis and eventual outcomes are warranted.

Lastly, there were expected statistically significant differences in AOD by geographic location, region [61], and county characteristics $[14,33]$, particularly by variation in county median income and region. While we could not approximate actual contribution to variance by these factors given software limitations, the percent change in both likelihood ratio testing and in adjusted $r$-square in the comparison of simple regression models suggests that well beyond individual and family characteristics in this higher SES sample (adj $R$-sq $=0.43$ ), geographic factors greatly contribute to variance in AOD (adj $R$-sq $=0.58$ ). This confirms previous reports that increased community access to diagnosis is associated with earlier AOD [33] and therefore is an identifiable area of opportunity for promoting increased awareness, screening, and services in more rural and Southern locations in the US.

4.3. Limitations. There are several limitations to this study. First, because this is a convenience sample, we are unable to approach true prevalence or true changes in AOD or AOC over time and any differences we report reflect only the registry population. There is some selection bias because families in IAN tend to be of higher socioeconomic status; nearly 50\% have maternal education attainment of bachelor's degree or higher, while the national average for adult women is 30\% [62]; however, this difference is similar to the bias in the majority of nonepidemiologic clinic-based and other survey-based studies. These same families may also be more likely to have earlier AOD overall, regardless of socioeconomic status. Nevertheless, comparisons of characteristics across IAN data are valuable in understanding differential factors influencing access to ASD care in this sample with multiple known (higher socioeconomic status and Internet usage) and unknown biases, which may lead to differential usage of health care systems.

In terms of information bias presented by an internetbased registry, we have previously discussed [63] the growing research supporting the validity of web-collected data [64]. 
ASD diagnoses within the online IAN registry have been clinically validated ( $n=107$ ) [46] and verified [47], confirming that the registry is a reliable modality for collecting clinical information. The detailed questions on all variables within IAN improve reliability; we further limited data to exclude families reporting improbable or inconsistent responses to maximize recall reliability specifically for AOC and AOD.

\section{Conclusion}

Our study suggests that multiple individual and family-level factors, as well as geographic characteristics (region and county income) affect AOD and often AOC, contributing to delay in initial diagnosis of ASD and entry into treatment, including early intervention. Two randomized controlled trials have shown that intervention for 2-year-olds that blends strategies based on principles of developmental and learning sciences results in significant language and cognitive improvements $[9,65]$ and social improvements [65].

The earliest possible timeframe for AOC and AOD in ASD is still being established; meanwhile, there is already definite variation with significant additive potential for improving timely diagnosis and subsequent receipt of services; this disparity could increase as more sophisticated screening tools emerge. Because no single factor can be identified, achieving equity in AOC, AOD and eventual intervention will require a multi-pronged approach that comprehensively addresses the smaller but cumulative cultural, educational, and health system factors which contribute to this variation. Our data can help public health officials and clinicians identify and explore modifiable disparities in AOC and AOD for potential interventions, such as for underrepresented minorities and those living in more rural or Southern states.

\section{Abbreviations}

AOC: Age of parent first concern

AOD: Age of first diagnosis

ASD: Autism spectrum disorder

AS: Asperger syndrome/Asperger disorder

ID: Intellectual disability

IQR: Interquartile range.

\section{Acknowledgments}

This study was supported in part by Autism Speaks and HRSA R40 MC 15594.

\section{References}

[1] L. Wing and D. Potter, "The epidemiology of autistic spectrum disorders: is the prevalence rising?" Mental Retardation and Developmental Disabilities Research Reviews, vol. 8, no. 3, pp. 151-161, 2002.

[2] Autism and Developmental Disabilities Monitoring Network Surveillance Year 2006 Principal Investigators, "Prevalence of autism spectrum disorders-autism and developmental disabilities monitoring network, United States, 2006," MMWR Surveillance Summaries, vol. 58, no. SS-10, pp. 1-20, 2009.
[3] American Psychiatric Association, "Disorders usually first diagnosed in infancy, childhood, or adolescence," in Diagnostic and Statistical Manual of Mental Disorders, American Psychiatric Association, Arlington, Va, USA, 4th edition, 2000.

[4] M. L. Ganz, "The lifetime distribution of the incremental societal costs of autism," Archives of Pediatrics and Adolescent Medicine, vol. 161, no. 4, pp. 343-349, 2007.

[5] T. T. Shimabukuro, S. D. Grosse, and C. Rice, "Medical expenditures for children with an autism spectrum disorder in a privately insured population," Journal of Autism and Developmental Disorders, vol. 38, no. 3, pp. 546-552, 2008.

[6] R. J. Landa, K. C. Holman, and E. Garrett-Mayer, "Social and communication development in toddlers with early and later diagnosis of autism spectrum disorders," Archives of General Psychiatry, vol. 64, no. 7, pp. 853-864, 2007.

[7] R. Paul, "Interventions to improve communication in autism," Child and Adolescent Psychiatric Clinics of North America, vol. 17, no. 4, pp. 835-856, 2008.

[8] L. Zwaigenbaum, S. Bryson, C. Lord et al., "Clinical assessment and management of toddlers with suspected autism spectrum disorder: insights from studies of high-risk infants," Pediatrics, vol. 123, no. 5, pp. 1383-1391, 2009.

[9] G. Dawson, "Early behavioral intervention, brain plasticity, and the prevention of autism spectrum disorder," Development and Psychopathology, vol. 20, no. 3, pp. 775-803, 2008.

[10] E. Fombonne, "A wrinkle in time: from early signs to a diagnosis of autism," Journal of the American Academy of Child and Adolescent Psychiatry, vol. 48, no. 5, pp. 463-464, 2009.

[11] S. E. Bryson, S. J. Rogers, and E. Fombonne, "Autism spectrum disorders: early detection, intervention, education, and psychopharmacological management," Canadian Journal of Psychiatry, vol. 48, no. 8, pp. 506-516, 2003.

[12] C. P. Johnson, S. M. Myers, P. H. Lipkin et al., "Identification and evaluation of children with autism spectrum disorders," Pediatrics, vol. 120, no. 5, pp. 1183-1215, 2007.

[13] M. V. Johnston, A. Ishida, W. N. Ishida, H. B. Matsushita, A. Nishimura, and M. Tsuji, "Plasticity and injury in the developing brain," Brain and Development, vol. 31, no. 1, pp. $1-10,2009$.

[14] D. S. Mandell, K. H. Morales, M. Xie, L. J. Lawer, A. C. Stahmer, and S. C. Marcus, "Age of diagnosis among medicaid-enrolled children with autism, 2001-2004," Psychiatric Services, vol. 61, no. 8, pp. 822-829, 2010.

[15] J. Pinto-Martin and S. E. Levy, "Early diagnosis of autism spectrum disorders," Current Treatment Options in Neurology, vol. 6, no. 5, pp. 391-400, 2004.

[16] R. L. Young, N. Brewer, and C. Pattison, "Parental identification of early behavioural abnormalities in children with autistic disorder," Autism, vol. 7, no. 2, pp. 125-143, 2003.

[17] C. R. Hess and R. J. Landa, "Predictive and concurrent validity of parent concern about young children at risk for autism," Journal of Autism and Developmental Disorders. In press.

[18] F. Volkmar, K. Chawarska, and A. Klin, "Autism in infancy and early childhood," Annual Review of Psychology, vol. 56, pp. 315-336, 2005.

[19] A. M. Wetherby, J. Woods, L. Allen, J. Cleary, H. Dickinson, and C. Lord, "Early indicators of autism spectrum disorders in the second year of life," Journal of Autism and Developmental Disorders, vol. 34, no. 5, pp. 473-493, 2004.

[20] S. J. Rogers, "What are infant siblings teaching us about autism in infancy?" Autism Research, vol. 2, no. 3, pp. 125-137, 2009.

[21] S. E. Bryson, L. Zwaigenbaum, J. Brian et al., "A prospective case series of high-risk infants who developed autism," Journal 
of Autism and Developmental Disorders, vol. 37, no. 1, pp. 12 24, 2007.

[22] R. Landa, "Early communication development and intervention for children with autism," Mental Retardation and Developmental Disabilities Research Reviews, vol. 13, no. 1, pp. 16-25, 2007.

[23] K. Chawarska, R. Paul, A. Klin, S. Hannigen, L. E. Dichtel, and F. Volkmar, "Parental recognition of developmental problems in toddlers with autism spectrum disorders," Journal of Autism and Developmental Disorders, vol. 37, no. 1, pp. 62-72, 2007.

[24] W. L. Stone, E. L. Hoffman, S. E. Lewis, and O. Y. Ousley, "Early recognition of autism: parental reports vs clinical observation," Archives of Pediatrics and Adolescent Medicine, vol. 148, no. 2, pp. 174-179, 1994.

[25] A. De Giacomo and E. Fombonne, "Parental recognition of developmental abnormalities in autism," European Child and Adolescent Psychiatry, vol. 7, no. 3, pp. 131-136, 1998.

[26] A. Baghdadli, M. C. Picot, C. Pascal, R. Pry, and C. Aussilloux, "Relationship between age of recognition of first disturbances and severity in young children with autism," European Child and Adolescent Psychiatry, vol. 12, no. 3, pp. 122-127, 2003.

[27] D. Schendel and T. K. Bhasin, "Birth weight and gestational age characteristics of children with autism, including a comparison with other developmental disabilities," Pediatrics, vol. 121, no. 6, pp. 1155-1164, 2008.

[28] A. B. Short and E. Schopler, "Factors relating to age of onset in autism," Journal of Autism and Developmental Disorders, vol. 18, no. 2, pp. 207-216, 1988.

[29] K. A. Twyman, R. A. Maxim, T. L. Leet, and M. H. Ultmann, "Parents' developmental concerns and age variance at diagnosis of children with autism spectrum disorder," Research in Autism Spectrum Disorders, vol. 3, no. 2, pp. 489-495, 2009.

[30] K. D. Ellingson, M. J. Briggs-Gowan, A. S. Carter, and S. M. Horwitz, "Parent identification of early emerging child behavior problems: predictors of sharing parental concern with health providers," Archives of Pediatrics and Adolescent Medicine, vol. 158, no. 8, pp. 766-772, 2004.

[31] D. S. Mandell, K. H. Morales, M. Xie, D. Polsky, A. Stahmer, and S. C. Marcus, "Factors associated with age of diagnosis among medicaid-enrolled children with autism spectrum disorders in the United States," in Proceedings of the International Meeting for Autism Research, May 2009.

[32] D. S. Mandell, L. D. Wiggins, L. A. Carpenter et al., "Racial/ethnic disparities in the identification of children with autism spectrum disorders," American Journal of Public Health, vol. 99, no. 3, pp. 493-498, 2009.

[33] P. T. Shattuck, M. Durkin, M. Maenner et al., "Timing of identification among children with an autism spectrum disorder: findings from a population-based surveillance study," Journal of the American Academy of Child and Adolescent Psychiatry, vol. 48, no. 5, pp. 474-483, 2009.

[34] D. S. Mandell, M. M. Novak, and C. D. Zubritsky, "Factors associated with age of diagnosis among children with autism spectrum disorders," Pediatrics, vol. 116, no. 6, pp. 1480-1486, 2005.

[35] P. A. Filipek, P. J. Accardo, G. T. Baranek et al., "The screening and diagnosis of autistic spectrum disorders," Journal of Autism and Developmental Disorders, vol. 29, no. 6, pp. 439484, 1999.

[36] M. Yeargin-Allsopp, C. Rice, T. Karapurkar, N. Doernberg, C. Boyle, and C. Murphy, "Prevalence of autism in a US metropolitan area," Journal of the American Medical Association, vol. 289, no. 1, pp. 49-55, 2003.

[37] P. Howlin and A. Moore, "Diagnosis in autism-a survey of over 1200 patients in the UK," Autism, vol. 1, no. 2, pp. 135162, 1997.

[38] R. P. Goin-Kochel, V. H. Mackintosh, and B. J. Myers, "How many doctors does it take to make an autism spectrum diagnosis?" Autism, vol. 10, no. 5, pp. 439-451, 2006.

[39] P. Howlin and A. Asgharian, "The diagnosis of autism and asperger syndrome: findings from a survey of 770 families," Developmental Medicine and Child Neurology, vol. 41, no. 12, pp. 834-839, 1999.

[40] K. C. Thomas, A. R. Ellis, C. McLaurin, J. Daniels, and J. P. Morrissey, "Access to care for autism-related services," Journal of Autism and Developmental Disorders, vol. 37, no. 10, pp. 1902-1912, 2007.

[41] D. S. Mandell and R. Palmer, "Differences among states in the identification of autistic spectrum disorders," Archives of Pediatrics and Adolescent Medicine, vol. 159, no. 3, pp. 266269, 2005.

[42] R. F. Palmer, S. Blanchard, C. R. Jean, and D. S. Mandell, "School district resources and identification of children with autistic disorder," American Journal of Public Health, vol. 95, no. 1, pp. 125-130, 2005.

[43] G. S. Liptak, L. B. Benzoni, D. W. Mruzek et al., "Disparities in diagnosis and access to health services for children with autism: data from the national survey of children's health," Journal of Developmental and Behavioral Pediatrics, vol. 29, no. 3, pp. 152-160, 2008.

[44] C. Y. Chen, C. Y. Liu, W. C. Su, S. L. Huang, and K. M. Lin, "Urbanicity-related variation in help-seeking and services utilization among preschool-age children with autism in Taiwan," Journal of Autism and Developmental Disorders, vol. 38, no. 3, pp. 489-497, 2008.

[45] Centers for Disease Control, "Prevalence of autism spectrum disorders-autism and developmental disabilities monitoring network, 14 sites, United States, 2002," MMWR Surveillance Summaries, vol. 56, no. SS01, pp. 12-28, 2007.

[46] H. Lee, A. R. Marvin, T. Watson et al., "Accuracy of phenotyping of autistic children based on internet implemented parent report," American Journal of Medical Genetics Part B, vol. 153B, no. 6, pp. 1119-1126, 2010.

[47] A. M. Daniels, R. E. Rosenberg, J. K. Law, C. Lord, W. E. Kaufmann, and P. A. Law, "Stability of initial autism spectrum disorder diagnoses in community settings," Journal of Autism and Developmental Disorders, vol. 41, no. 1, pp. 110-121, 2011.

[48] A. Marvin, J. K. Law, C. A. Cohen, and P. A. Law, "Creating the digital melting pot: lessons from a web-based national autism registry and research project," in Proceedings of the International Meeting for Autism Research, May 2009.

[49] US Census Bureau, "Census Divisions: Cartographic Boundary Files Descriptions and Metadata," 2008, http://www.census .gov/geo/www/cob/dv_metadata.html.

[50] National Center for Health Statistics, 2010, 2006 NCHS Urban-rural classification scheme for counties, http://www .cdc.gov/nchs/r\&d/rdc_urbanrural.htm.

[51] W. L. Stone, C. R. McMahon, P. J. Yoder, and T. A. Walden, "Early social-communicative and cognitive development of younger siblings of children with autism spectrum disorders," Archives of Pediatrics and Adolescent Medicine, vol. 161, no. 4, pp. 384-390, 2007. 
[52] M. Wallentin, "Putative sex differences in verbal abilities and language cortex: a critical review," Brain and Language, vol. 108, no. 3, pp. 175-183, 2009.

[53] A. R. Wimsatt, A. Rozga, and D. L. Robins, "Differences in parental reports of behavior: a possible factor in disparities of age at diagnosis of autism spectrum disorders in africanamericans," in Proceedings of the International Meeting for Autism Research, May 2009.

[54] D. S. Mandell and M. Novak, "The role of culture in families' treatment decisions for children with autism spectrum disorders," Mental Retardation and Developmental Disabilities Research Reviews, vol. 11, no. 2, pp. 110-115, 2005.

[55] T. Overton, C. Fielding, and R. G. de Alba, "Differential diagnosis of Hispanic children referred for autism spectrum disorders: complex issues," Journal of Autism and Developmental Disorders, vol. 37, no. 10, pp. 1996-2007, 2007.

[56] L. D. Wiggins, J. Baio, and C. Rice, "Examination of the time between first evaluation and first autism spectrum diagnosis in a population-based sample," Journal of Developmental and Behavioral Pediatrics, vol. 27, supplement 2, pp. S79-S87, 2006.

[57] E. Fombonne, "Epidemiologic studies of pervasive developmental disorders," in Handbook of Autism and Pervasive Developmental Disorders, Diagnosis, Development, Neurobiology, and Behavior, F. Volkmar, R. Paul, A. Klin, and D. J. Cohen, Eds., pp. 42-69, John Wiley \& Sons, New York, NY, USA, 3rd edition, 2005.

[58] D. S. Mandell, J. Listerud, S. E. Levy, and J. A. PintoMartin, "Race differences in the age at diagnosis among medicaid-eligible children with autism," Journal of the American Academy of Child and Adolescent Psychiatry, vol. 41, no. 12, pp. 1447-1453, 2002.

[59] S. Begeer, S. E. Bouk, W. Boussaid, M. M. Terwogt, and H. M. Koot, "Underdiagnosis and referral bias of autism in ethnic minorities," Journal of Autism and Developmental Disorders, vol. 39, no. 1, pp. 142-148, 2009.

[60] Child and Adolescent Health Measurement Initiative, "2005/06 National Survey of Children with Special Health Care Needs," 2009, http://www.cshcndata.org.

[61] H. M. J. Ouellette-Kuntz, H. Coo, M. Lam et al., "Age at diagnosis of autism spectrum disorders in four regions of canada," Canadian Journal of Public Health, vol. 100, no. 4, pp. 268-273, 2009.

[62] US Census Bureau, "Educational Attainment-People 25 Years Old and Over (PINC-03)," 2009, http://pubdb3.census.gov/macro/032006/perinc/new03_028.htm.

[63] R. E. Rosenberg, A. M. Daniels, J. K. Law, P. A. Law, and W. E. Kaufmann, "Trends in autism spectrum disorder diagnoses: 1994-2007," Journal of Autism and Developmental Disorders, vol. 39, no. 8, pp. 1099-1111, 2009.

[64] S. D. Gosling, S. Vazire, S. Srivastava, and O. P. John, "Should we trust web-based studies? A comparative analysis of six preconceptions about internet questionnaires," American Psychologist, vol. 59, no. 2, pp. 93-104, 2004.

[65] R. J. Landa, K. C. Holman, A. H. O’Neill, and E. A. Stuart, "Intervention targeting development of socially synchronous engagement in toddlers with autism spectrum disorder: a randomized controlled trial," Journal of Child Psychology and Psychiatry and Allied Disciplines, vol. 52, no. 1, pp. 13-21, 2011. 


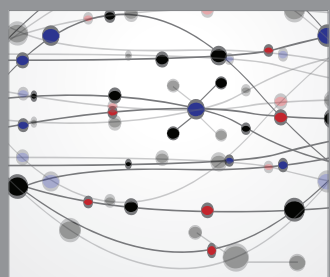

The Scientific World Journal
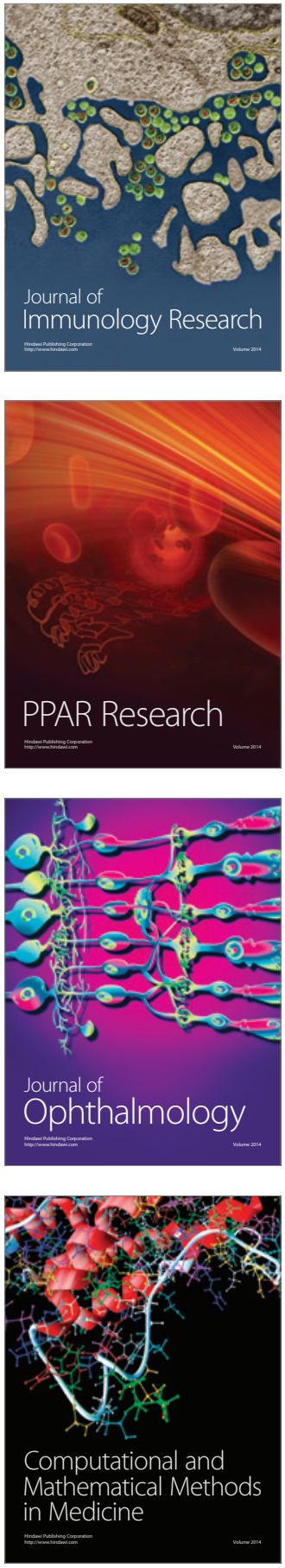

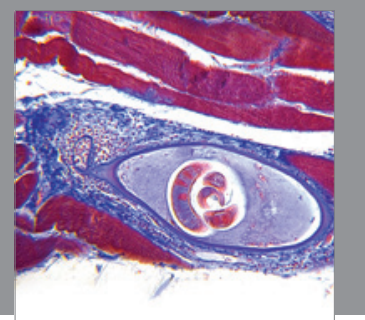

Gastroenterology

Research and Practice
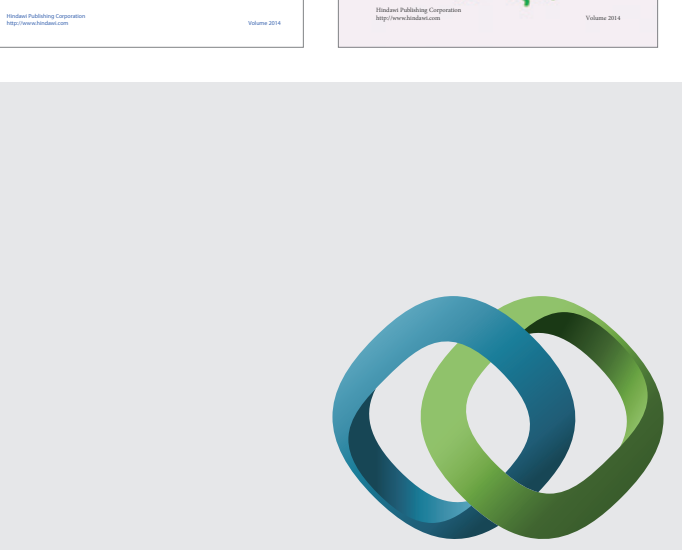

\section{Hindawi}

Submit your manuscripts at

http://www.hindawi.com
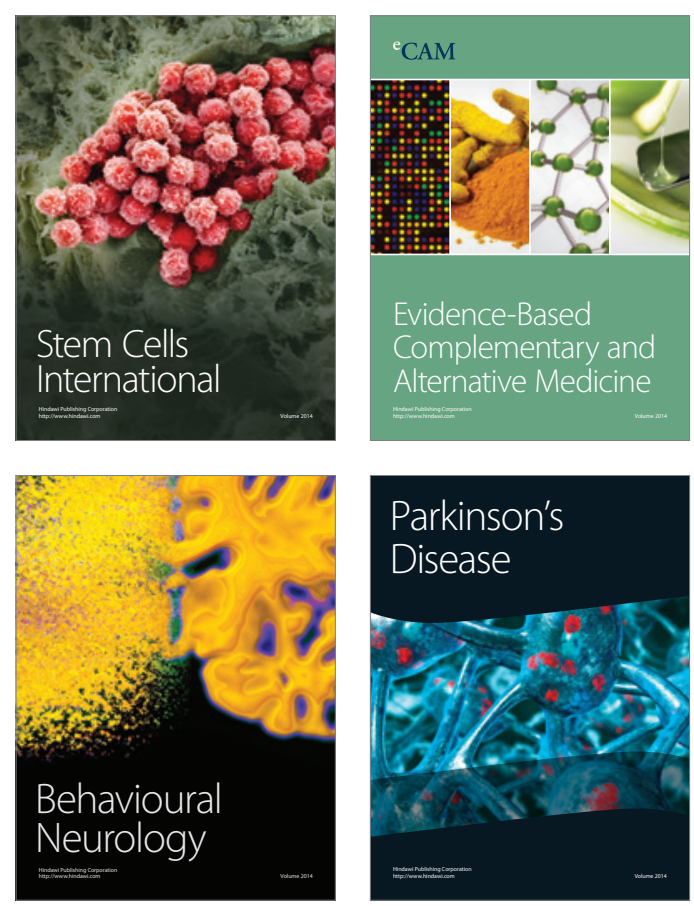

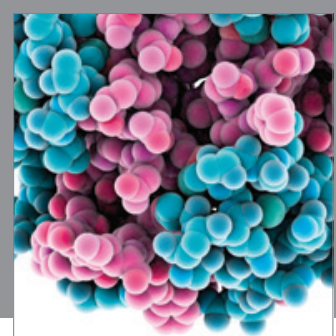

Journal of
Diabetes Research

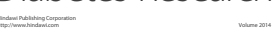

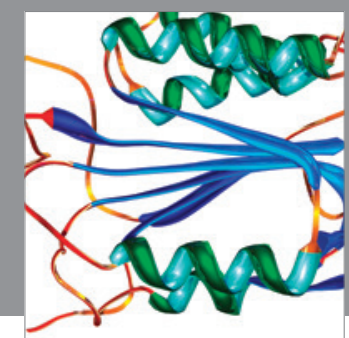

Disease Markers
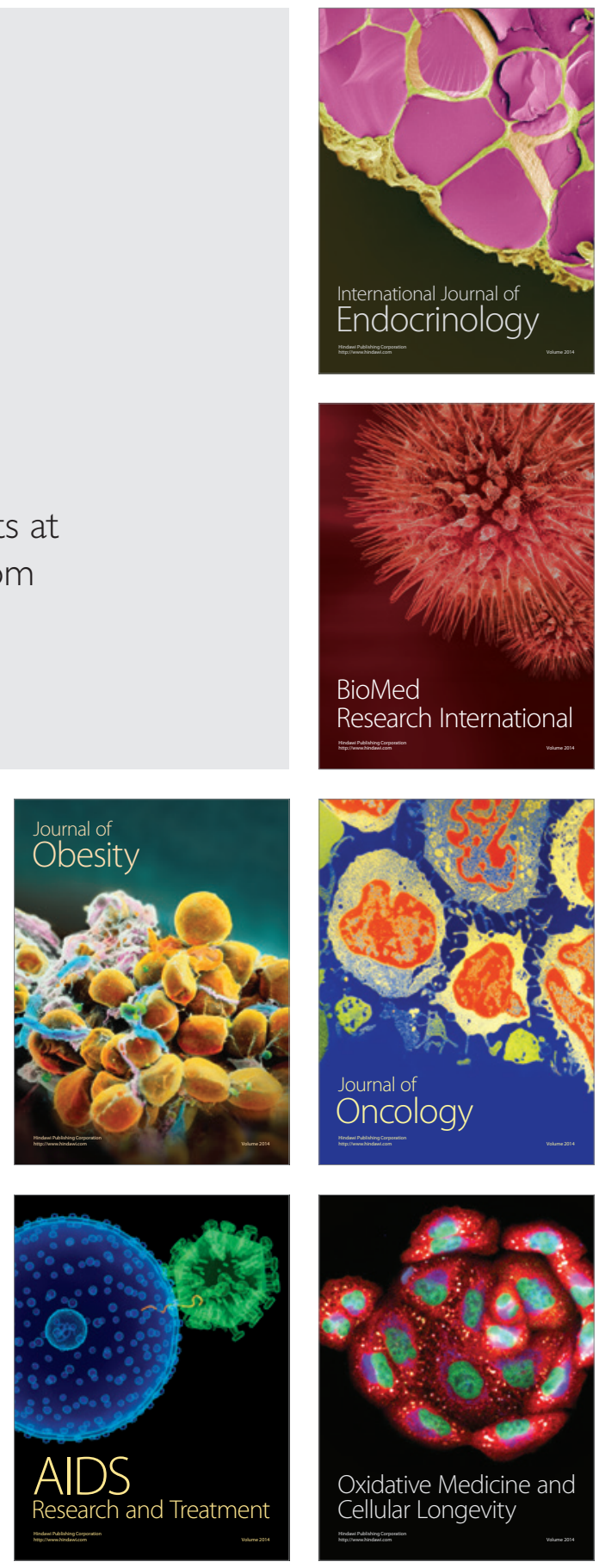